\title{
EPR Everywhere
}

\author{
Joshua R. Biller ${ }^{1}$ (D) . Joseph E. McPeak ${ }^{2,3}$ (D)
}

Received: 9 August 2020 / Revised: 16 October 2020 / Accepted: 6 December 2020 /

Published online: 24 January 2021

(c) The Author(s), under exclusive licence to Springer-Verlag GmbH, AT part of Springer Nature 2021

\begin{abstract}
This review is inspired by the contributions from the University of Denver group to low-field EPR, in honor of Professor Gareth Eaton's 80th birthday. The goal is to capture the spirit of innovation behind the body of work, especially as it pertains to development of new EPR techniques. The spirit of the DU EPR laboratory is one that never sought to limit what an EPR experiment could be, or how it could be applied. The most well-known example of this is the development and recent commercialization of rapid-scan EPR. Both of the Eatons have made it a point to remain knowledgeable on the newest developments in electronics and instrument design. To that end, our review touches on the use of miniaturized electronics and applications of single-board spectrometers based on software-defined radio (SDR) implementations and single-chip voltage-controlled oscillator (VCO) arrays. We also highlight several non-traditional approaches to the EPR experiment such as an EPR spectrometer with a "wand" form factor for analysis of the OxyChip, the EPR-MOUSE which enables non-destructive in situ analysis of many non-conforming samples, and interferometric EPR and frequency swept EPR as alternatives to classical high Q resonant structures.
\end{abstract}

\section{Introduction}

This review is written in honor of the 80th birthday of Professor Gareth Eaton, and in celebration of the work he and Professor Sandra Eaton have accomplished for EPR at the University of Denver. Traditionally a review summarizes and makes commentary on a vast body of work. While there is some of that here, this review is predominantly focused on trying to capture the modus operandi of the

Joshua R. Biller

jbiller@tda.com

1 TDA Research, Inc., Golden, CO 80433, USA

2 University of Denver, Denver, CO 80210, USA

3 Berlin Joint EPR Laboratory and EPR4Energy, Department Spins in Energy Conversion and Quantum Information Science (ASPINS), Helmholtz-Zentrum Berlin für Materialien und Energie GmbH, Hahn-Meitner-Platz 1, 14109 Berlin, Germany 
Eaton laboratory which has facilitated such successes. If we could distill that into the "Eaton Rules," it might go something like this:

(1) Read, everything (patents, primary literature, popular science) and do so continually.

(2) Be aware of advances in other technologies-you never know when someone else has already solved a problem that has you stumped.

(3) Never assume the EPR experiment is bound to only one size/shape or implementation.

(4) Make friends with RF engineers.

(5) Experiments which are "impossible" today will not be tomorrow.

With that in mind, we aim to put the Eatons' work on the development of lowfield EPR, chiefly their demonstrations on signal sensitivity and development of rapid-scan, in the context of the current state of the art related to magnetic resonance (both nuclear and paramagnetic resonance) which could be used to expand these experiments beyond the laboratory. We review a portion of the Eatons' work demonstrating that signal strength at low magnetic field is robust and useful, since reducing the field requirement for the experiment is one way to make the instrument more portable for in-field applications. Features of low-field EPR which are different from the high field and how they might (or have been) used are discussed. A short commentary on NMR ventures outside the laboratory follows, as a magnetic resonance technique which has been in existence for almost 70 years, to help reimagine the scope of EPR experiments outside the laboratory. We touch on advances in digital electronics which are now widely available for low magnetic field experiments, including demonstration of the first EPR spectrometer built using a software-defined radio (SDR) platform. Specific examples of non-traditional EPR experiment designs are reviewed which were developed at both low magnetic field (OxyChip, EPR-MOUSE) and also high field (EPRinterferometer, "MR to Go").

An ensemble of spins (electron or nuclear) in a magnetic field yields a quantity and richness of information that is unparalleled by other techniques. As Purcell has noted in his 1952 Nobel Prize address, there is a sense of wonder and delight at the "delicate motion" residing in "all things around us, revealing itself only to him who looks for it." Practically however, the whole of the information produced by the spin ensemble is a bulk electrical signal coming from a resonant (or sometimes non-resonant) structure along an electrical conductor to a detector (with various additional steps through pre-amplifiers and filters). The detector picks up many other electrical signals as well. It is the separation of the spin resonance signal we wish to observe (specificity) from the cacophony of other signals that is desirable. This is accomplished by recognizing that "noise" in this sense is a combination of unwanted contributions from electronics and the environment. Once characterized these "noise" contributions can be minimized or avoided to clarify the spin resonance signal we seek. This is a fundamental driver of the Eatons' work related to EPR methodology. Professor James Hyde taught us all 
that "spins are everywhere" [1]. The work of Professors Gareth and Sandra Eaton inspires us to find and measure the spins everywhere they are.

\section{Contributions to the Low Magnetic Field at the University of Denver}

The contributions made by Gareth and Sandra Eaton and their laboratory at the University of Denver (DU) to the low-field EPR community have been widespread. Among their largest contributions to low magnetic field applications have been small EPR imaging systems [2, 3], Q-switching crossed-loop resonators [4, 5], and rapid-scan [6]. Work at the University of Denver along with the University of Maryland [7-12], the Ohio State University [13-18], Dartmouth [19-23], the University of Chicago [24-42], and the NIH [43-51] continues to demonstrate the utility of low-field EPR for pre-clinical EPR imaging. Expansion of these efforts continues at West Virginia University under the guidance of Tseytlin, Driesschaert and Khramtsov [52-55]. Low-field EPR spectroscopy and imaging applied to pre-clinical applications forms an outstanding basis from which to build in-field applications of materials analysis and non-destructive evaluation (NDE). The great unexplored potential of low-field EPR stems from the combination of many incorrect ideas about sensitivity, instrument design, magnet selection and low-field physics.

In both EPR and NMR, the signal intensity depends on the Boltzmann distribution of spin states according to Eq. (1).

$$
\frac{N_{\text {High }}}{N_{\text {Low }}}=e^{\left(\frac{-\gamma \hbar B_{0}}{2 \pi k T}\right)} .
$$

From here it is easy to see why the first major push in both EPR and NMR was to higher magnetic fields and lower temperatures, as these increase the magnetization which can be detected in the experiment. However, the concentration and volume of spins will also determine how strong of a signal may be observed in an experiment. That spin concentration and volume can overcome deficiencies in physical constants is both fortuitous and evident in NMR considering the proton gyromagnetic constant is $658 \times$ smaller than that of the electron. Both EPR and NMR began at low magnetic fields, and increasing field strength was a straightforward way to mask the underdeveloped analog electrical components available in the 1940s and 1950s. If one could travel back in time to deliver low noise arbitrary waveform generators and high-speed digitizers to Bloch, Purcell, Pound and Zavoisky, the common EPR and NMR experiments we know today might look very different.

\subsection{Sensitivity in the Low Magnetic Field}

Beginning in 1995 the Eatons, together with Dr. George Rinard and Richard Quine at DU, began dispelling a long-held belief that sensitivity at low magnetic fields would be terribly low and therefore an endeavor not worth pursuing. This was started by demonstrating the relaxation and lineshape of irradiated vitreous silica 
at L-, S-, C- and X-band, all recorded at DU [56]. They later reported in 1996 the construction of the L-band spectrometer used in those measurements, demonstrating weak pitch measurements at low field that corresponded well with similar measurements made at X-band after considering the ratio of frequencies used ( 5.4) [57].

The signal-to-noise ratio (SNR) has two components: signal and noise. The maximum signal is determined by the physical interaction of the applied magnetic field with the spins, their spin state dictated by concentration, volume and the temperature (and also the ability of the user to select experimental parameters correctly) [58]. The fundamental lower limit of the noise component is the thermal noise. In addition to this limit the noise is a function of how well the spectrometer electrical paths and resonator have been designed and constructed, as well as the combined performance of all the individual components, particularly the microwave source and detection amplifier. After careful consideration of all spectrometer components, DU reported SNR of 35 with weak pitch samples and $1 \mu \mathrm{M}$ sensitivity with the L-band spectrometer described in 1996 [57].

The first comparison with well-characterized spectrometers at X-band and S-band was made in 1999 using an irradiated fused quartz sample [59, 60]. After scaling the comparison for differences in spectrometer gain, resonator Q factor and filling factor, the Eaton laboratory found the SNR at $9.5 \mathrm{GHz}$ to be $9.5 \times$ larger than at S-band, for the two spectrometers studied. Since the noise floor varies between spectrometers (even at the same frequency), the comparison value was stated with the caveat that the comparison was valid only for the two spectrometers used. Similar studies were performed in 2002 from $248 \mathrm{MHz}$ to $1.4 \mathrm{GHz}$ [61] and then from $250 \mathrm{MHz}$ to $9.1 \mathrm{GHz}$ with a midpoint at $1.5 \mathrm{GHz}$ [62]. These studies resulted in the conclusion that as sample size was scaled inversely with operating frequency (up to $19 \mathrm{~mm}$ i.d. at $250 \mathrm{MHz}$ ), the signal amplitude at constant $B_{1}$ scales as $\omega^{-1 / 4}$. Signal amplitudes were compared across the three frequencies, rather than SNR, because at the time of publication the noise floor in the VHF spectrometer was limited by the noise characteristics of the $250 \mathrm{MHz}$ RF source. The quality of components has advanced considerably since these reported works, with EPR occasionally driving component development. Manufacturers are now developing purpose-built EPR components at low frequencies for low-field EPR applications. For example, several high-quality RF amplifiers in the 100-900 MHz range are offered by Tomco RF and power supplies which allow magnetic field reversal for low-field RS experiments are offered by CAEN [63].

\subsection{Rapid-scan}

Development of rapid-scan (RS) at the University of Denver [6, 64-68] was another milestone that greatly improved sensitivity by changing how the data are collected [69]. At high magnetic fields rapid-scan has been applied to samples whose long relaxation times make $\mathrm{CW}$ measurements difficult $[70,71]$, to improve spin trapping experiments [72], and expanded to include measurement of immobilized nitroxides with wide rapid-scans [73]. The stitching of multiple spectra together has been used to perform experiments on transition metal species 
[74]. At DU, RS was employed to decrease the limit of detection down to $5 \mu \mathrm{M}$ in imaging experiments using phantoms at $250 \mathrm{MHz}$ [75]. This work was possible because of earlier work developing rapid-scan imaging of nitroxide radicals at $250 \mathrm{MHz}$ where mechanical resonances induced by the oscillating rapid-scan field were investigated [76], a good example of improving SNR by reducing the noise floor through improvements in engineering.

Rapid-scan is now routinely used in low-frequency applications at DU and has been used for 4D imaging [77], dynamic imaging of redox status [78] and multicomponent phantom imaging [79]. An even more recent development regarding the rapid-scan background is to remove its influence based on how the experiment is carried out, rather than modifying the rapid-scan resonator. Specifically, for lowfield applications, the Eaton laboratory has developed a field reversal method that largely minimizes the RS background [63]. This field reversal method is currently not accessible at high fields and exemplifies a strategy which is accessible to lowfield applications exclusively.

EPR at low magnetic field has long been believed to be impractical, unfeasible and poorly understood due to lower SNR observed relative to higher field applications. Much of the work from the DU laboratory has refuted those beliefs. Electronics have become inexpensive and widely available. The physics are becoming better understood, but still represent an exciting new frontier for fundamental research. Pre-clinical imaging is the most well characterized low-field EPR application, but even this is only scratching the surface of what may be explored.

\section{What Information Could We Use in the Low field?}

The power, sensitivity and selectivity of EPR are well understood at high magnetic field strengths and frequencies - the main drawback is sample preparation. Sample requirements are significantly different at low magnetic field-both in size of resonator/active volume of the $B_{1}$ field and geometries which can be used to generate the $B_{0}$ field. Typically, a larger active volume may be used in low-field applications enabling the use of larger samples. This may be problematic in situations where little sample is available; however, this may be advantageous for in situ EPR applications when samples of interest are larger than would be measurable using high-field EPR techniques. There remains the incorrect perception that work in low-field EPR is too difficult to tackle - that sensitivities are too low, and the physics too intimidating due to the presence of transitions which are formally forbidden at high magnetic field.

The information which can be gained from g- and A-anisotropy in EPR spectra recorded at different temperatures and frequencies is well known [80]. In typical EPR experiments at higher magnetic field, consideration of forbidden transitions has been neglected in all, but a few cases, such as applications of parallel mode EPR $[81,82]$. However, these experiments are gaining new interest for designing qubits for quantum computing [83] and also because they may play a role in dynamic nuclear polarization (DNP) [84, 85]. 


\subsection{The Role of g-tensor-Reduced Spectral Width Relaxes Experiment Requirements}

The base physical interaction of the EPR experiment is the magnetic moment of the electron coupling to the magnetic field. The proportionality constant which describes the magnitude of the coupling is the gyromagnetic ratio, and deviation of this value from the free electron value is characteristic of the environment occupied by the unpaired electron. The g-factor is commonly referred to as a fingerprint of the electron environment, similar to chemical shifts in NMR experiments. The resolution in anisotropic g-factor components $\left(g_{x}, g_{y}, g_{z}\right)$ is proportional to microwave frequency, such that information from $g$-factor anisotropy is a form of high-field fingerprint. This high-field g-factor fingerprint has been extensively studied in both transition metal and lanthanide spectroscopy and has been thoroughly described by Pilbrow and others [86, 87]. This type of high-field fingerprinting has proven very useful in analyses of iron-sulfur proteins [88].

As the microwave frequency decreases, the anisotropic g-components collapse and the spectrum narrows. When relying only on anisotropic g-factor information, this becomes a powerful reason to avoid lower magnetic fields. However, the collapse of g-anisotropy and narrowing of the total spectral width at low frequencies and field strengths makes the EPR experiment for transition metals easier from the standpoint of an in situ CW or RS experiment. The assumption is made that transition metal species have relaxation rates which are too fast at room temperature to be acquired with current in situ pulse EPR spectrometers such as the unilateral EPR system used for OxyChip measurements, described later; however, this is likely not the case for in situ CW and RS spectrometers. As an illustration of the spectral narrowing expected as field and frequency decrease, a general $\mathrm{Cu}(\mathrm{II})$ complex with a natural abundance mixture of ${ }^{63} \mathrm{Cu}$ and ${ }^{65} \mathrm{Cu}$ was simulated in MATLAB using EasySpin at four frequencies from $34 \mathrm{GHz}$ to $500 \mathrm{MHz}$ (Fig. 1) [89]. The spectral width narrows from $132.8 \mathrm{mT}(1328 \mathrm{G})$ at $34 \mathrm{GHz}$ to $32.2 \mathrm{mT}(322 \mathrm{G})$ at $500 \mathrm{MHz}$. Extending the simulation down to $150 \mathrm{MHz}$ reduces the spectral width to $26.8 \mathrm{mT}(268 \mathrm{G})$.

Currently, the widest single sweep reported for rapid-scan direct detection methods is $18.2 \mathrm{mT}(182 \mathrm{G})$, which is approaching the regime where entire transition metal spectra could be collected in one RS field sweep at a low enough magnetic field. Transition metal spectra have been recorded at higher fields using two different stepwise direct detection methods: field-stepped direct detection (FSDD) at the University of Denver [74] and non-adiabatic rapid-scan (NARS) at the Medical College of Wisconsin $[90,91]$ and would be even easier to apply to narrow spectra at low magnetic fields, if required at all. Additionally, RS has been performed via frequency sweeps using a static magnetic field, shifting the RS capabilities from the coil driver to the frequency generator [92, 93]. This technique is particularly enticing for low-field applications where high-resolution frequency sweeps may be possible with the current generation of commercially available arbitrary waveform generators (AWGs) and in non-resonant applications where considerations of bandwidth in relation to resonator $\mathrm{Q}$ are no longer necessary [94]. 

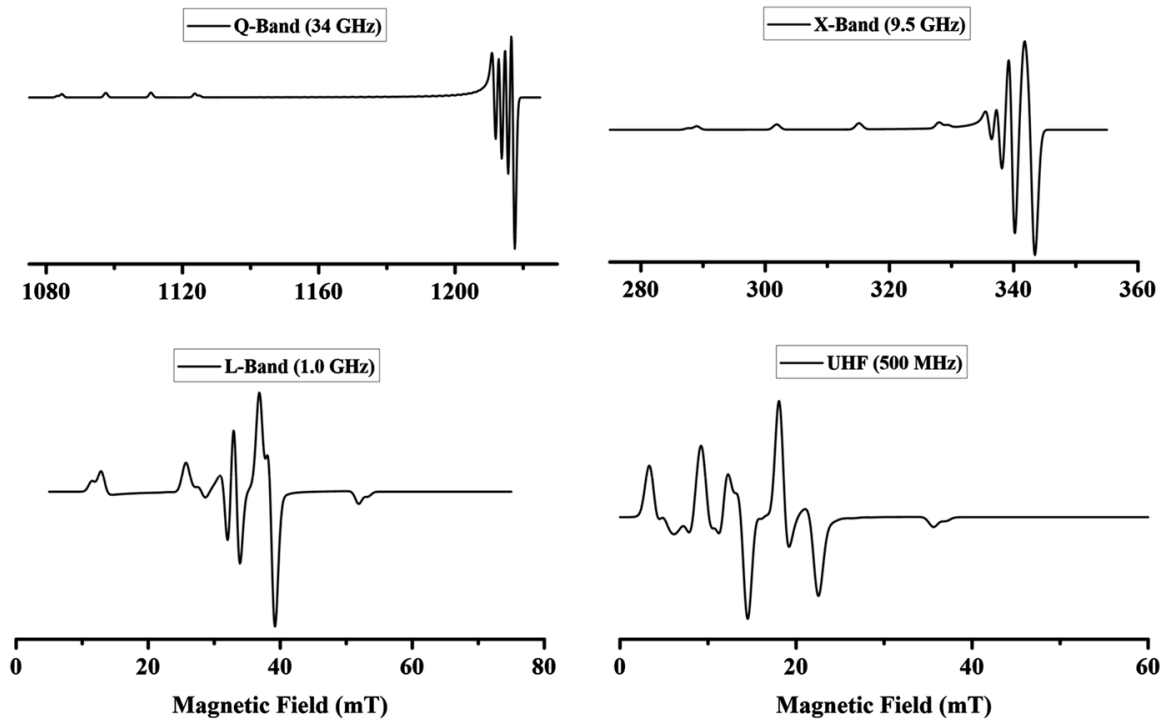

Fig. 1 Simulation of the rigid-limit spectrum of natural abundance mixture of $\mathrm{Cu}^{63} / \mathrm{Cu}^{65}$ at frequencies from $34 \mathrm{GHz}$ to $500 \mathrm{MHz}$ using pepper in EasySpin. The spectral width narrows from $132.8 \mathrm{mT}$ at $34 \mathrm{GHz}$ to $32.2 \mathrm{mT}$ at $500 \mathrm{MHz}, g_{x y}=2$ and $g_{z}=2.2, A_{x y}=50 \mathrm{MHz} A_{z}=400 \mathrm{MHz}$. The system linewidth is $1 \mathrm{mT}$

The reduced role of g-tensor fingerprinting at the low magnetic field follows if we consider the cases where the g-strain is not large. The case where g-strain makes an appreciable contribution to line shape is a unique one, both orientation selection studies at high-field and studies in the $2-3 \mathrm{GHz}$ region of low-field offer a complete picture of the ligand environment around a metal center of interest. This scenario is considered in Discussion section of the review.

\subsection{The Role of the A-tensor-the Low-Field "fingerprint"}

The hyperfine information relates to the interaction of the unpaired electron and nearby nuclear spins. The size and relative ratio of isotropic and anisotropic contributions reflects the ground state electron wave function of the paramagnetic center [95]. As a source of information in EPR, hyperfine coupling constants and their experimentally observed splitting patterns can report on both the intrinsic nuclear spin of the paramagnetic center and the structure of the ligand sphere via external nuclear interactions [95] as well as differentiate many characteristics of the electron environment, such as molecular structure, solvent polarity [96, 97], $\mathrm{pH}[98,99]$ and molecular tumbling [100]. Hyperfine splitting is observable down to a few tens to hundreds of $\mathrm{kHz}$ [95] and, at low magnetic fields, dominate the Zeeman interaction. The frequencies where the hyperfine interaction begins to supersede the Zeeman interaction depend on the magnitude of hyperfine coupling constants, which are on the order of one hundred $\mathrm{MHz}$ for small organic nitroxide radicals and several 
hundreds of $\mathrm{MHz}$ for transition metals. The number of allowed transitions increases with the number of coupled nuclei according to:

$$
N_{\mathrm{EPR}}=\prod_{k=1}^{m}\left(2 n_{K} I_{K}+1\right) \text {. }
$$

In the high-magnetic field case hyperfine splitting patterns from different groups of equivalent nuclei will overlap. In the low magnetic field case, additional splitting can arise from these equivalent nuclei that is separated and independently observable, whereas there is often considerable overlap seen at high magnetic fields.

Transition metal ions show large hyperfine couplings to the nucleus of the metal atom while also reporting ligand hyperfine interactions. From X-band $(9.5 \mathrm{GHz})$ and below, the hyperfine field is no longer negligible in comparison with the Zeeman interaction. Second-order effects at low field result in shifts in the positions of the lines in the empirically observed hyperfine splitting pattern. An illustrative example of two cases, simulated in MATLAB using EasySpin, compares the hyperfine interactions observed at both X-band (9.05 GHz) and L-band (1.25 GHz)(Fig. 2) [89]. The comparison is made between a $\mathrm{Cu}$ (II) paramagnetic center with four imidazole ligands and an isolated $\mathrm{Cu}$ (II) center. The nitrogen couplings are from Reference [101] and appear fully resolved at X-band. Even though their resolution is diminished at $1.25 \mathrm{GHz}$, there is still enough difference in the two spectra to separate the cases where four nitrogen nuclei are present compared to the isolated $\mathrm{Cu}$ (II) case.

Quantitative interpretation of hyperfine coupling requires quantum mechanical calculations [95]. Qualitative differences between hyperfine splitting may be used as a "fingerprint" allowing an effective and efficient way to explore new applications using low-field EPR. This type of fingerprinting has been investigated at VHF and $\mathrm{UHF}(\sim 250 \mathrm{MHz}, 700 \mathrm{MHz})$ in the Eaton laboratory in 2D spectral-spatial imaging experiments of hybrid phantoms containing ${ }^{14} \mathrm{~N}$ and ${ }^{15} \mathrm{~N}$ nitroxides and trityl radicals recorded by rapid-scan with sufficient SNR to differentiate the signals of each isotope present [77, 79]. Regardless of the type of information to be extracted from an EPR spectrum, the experiment can always be relied upon to generate more questions than those with which the operator started. In the case of samples and sampling environments new to EPR, low-field applications will generate the need for deeper analysis of individual components at higher magnetic field strengths to guide quantum mechanical calculations and interpretations of in situ spectra acquired at low magnetic fields. Thus, an increased effort to engage the outside world to a greater extent through the vehicle of low-field EPR does not replace the need for high-field EPR, but rather supports it.

\subsection{Different Modes of Detection-DNP-Detected EPR}

Low-field EPR and high-field EPR are combined with NMR in a dynamic nuclear polarization (DNP) experiment. This combination is both a source of new information on the materials under study [102] and a different type of detection scheme that is especially beneficial at low field. Some of the first low-field spectra of DMPO-OH were acquired using DNP-detected EPR [103] as early as 1992. At very 

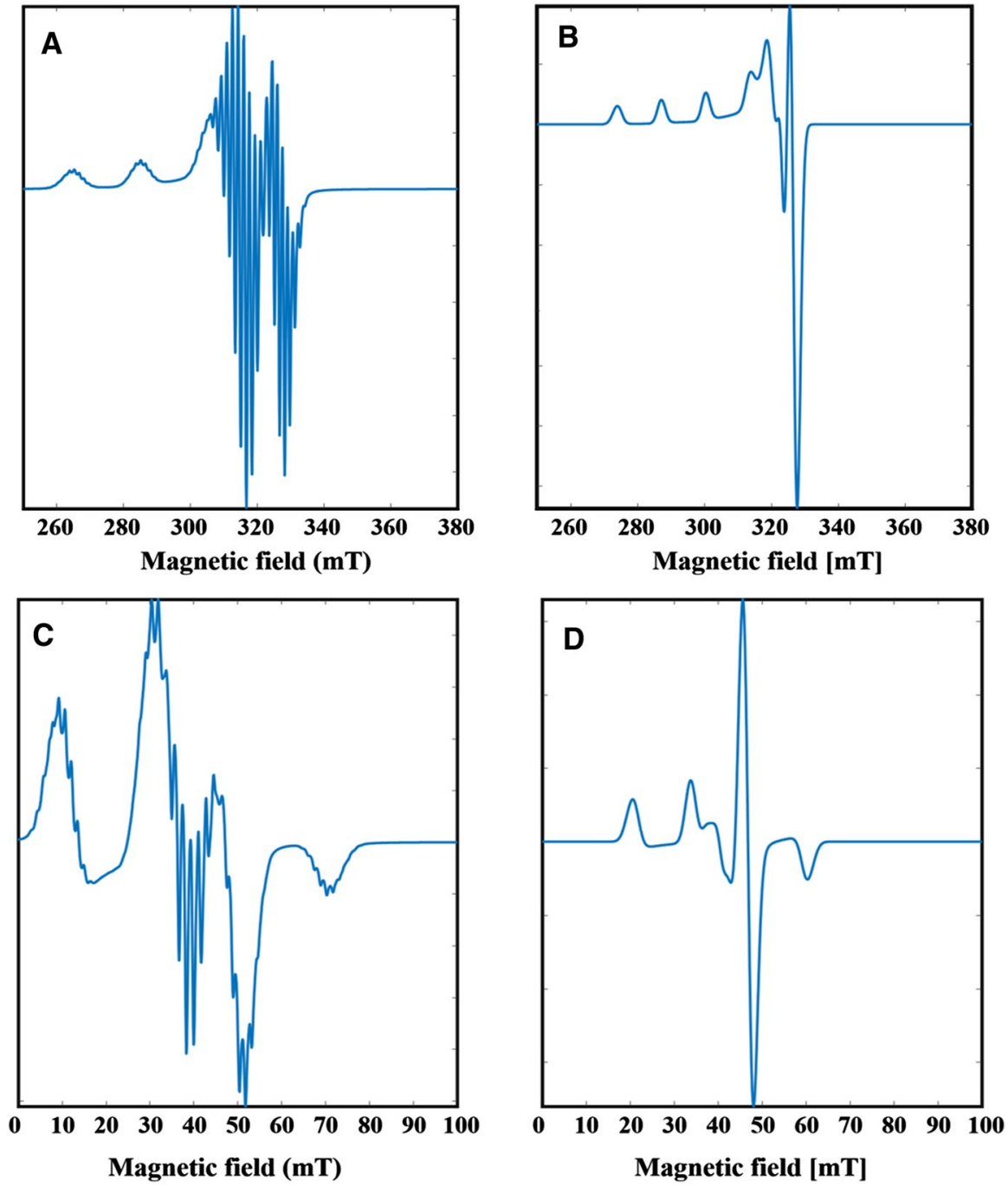

Fig. 2 Simulations of $\mathrm{Cu}$ (II) in different environments at $9.05 \mathrm{GHz}$ (a, b) and $1.25 \mathrm{GHz}$ (c, d). The example MATLAB simulation for $\mathrm{Cu}$ (II) with four imidazole ligands (nitrogen hyperfine coupling) is shown in a and $\mathbf{c}\left(g_{x y}=2.05, g_{z}=2.19, \mathrm{~A}(\mathrm{Cu})_{x y}=56.96 \mathrm{MHzm} \mathrm{A}(\mathrm{Cu})_{Z}=608.58 \mathrm{MHz}\right.$, $\mathrm{A}(\mathrm{N})_{x y}=43.47 \mathrm{MHz}, \mathrm{A}(\mathrm{N})_{z}=50.96 \mathrm{MHz}$ ). The example for a simple $\mathrm{Cu}$ (II) with natural abundance ${ }^{63} \mathrm{Cu}$ and ${ }^{65} \mathrm{Cu}$ is shown in $\mathbf{b}$ and $\mathbf{d}\left(g_{x y}=2\right.$ and $\left.g_{z}=2.2, A_{x y}=50 \mathrm{MHz} A_{z}=400 \mathrm{MHz}\right)$. Note that these simulations do not explicitly include the effect of $g$ - and A-strain

low magnetic fields, the maximum enhancement for solution DNP is predicted to be $\sim 2000 \times$ for nitroxides and is dependent on the strength of the hyperfine interaction of the radical [104]. Quantitative experimental exploration of this phenomenon is still in the very early stages $[105,106]$.

The combination of EPR and NMR into DNP experiments offers a number of advantages. Already developed in situ NMR only techniques already take advantage 
of pre-polarization at a higher magnetic field before analysis at a lower magnetic field. This is accomplished because the proton relaxation times are so much longer; appreciable polarization remains after a fast shuttle of a sample or fluid from a small higher field magnet to the analysis field. The reason for doing the measurement this way is to take advantage of high field polarization, but be able to do analysis on a sample whose size dictates the use of a low-field approach. In DNP the proton polarization can also be further enhanced by saturation of the electron transition. Thus, the enhancement from the saturation of the electron spin is further amplified by pre-polarization of the proton spins, improving sensitivity of low field applications. This type of field-cycled dynamic nuclear polarization (FC-DNP) was pioneered by David Lurie and co-workers and enabled the measurement of nitroxide radical spectra between 2 and $12 \mathrm{mT}(20-120 \mathrm{G})$ as early as 1991 [107, 108], and detection of spin-trapped hydroxyl $(\mathrm{OH} \cdot)$ radicals was reported in 1992 [103]. Full saturation of the electron transition is not required for the technique to provide spectral information on the EPR species [109].

In FC-DNP, as power is applied at the EPR frequency, the $B_{0}$ field is stepped to encompass the entire spectral width of the unpaired electron species. Comparison for the experimental results from nitroxides with theoretical predictions from Breit-Rabi second-order effects was in good agreement [110-112]. As long as the radical concentration is kept low, the nuclear relaxation times are on the order of 0.5-2 s [106]. The shift from pre-polarization fields to measurement fields, on the order of tens of milliseconds, results in little signal loss. The fact that FC-DNP does not require full saturation of the EPR transition makes it an intriguing idea for detection of transition metals at low magnetic field.

\section{How Far is Everywhere? Examples from Low-Field NMR}

While unilateral approaches (single-sided $B_{0}$ ) have only been applied for EPR within the last 10 years, there have been many variations in the NMR world dating back to the 1950s. More well-known examples are the NMR mobile-universal-surface-explorer (NMR-MOUSE), developed by Bernhard Bluemich and his colleagues beginning in 1996 [113], and the use of NMR in down-bore hole analysis in the petroleum industry. Unilateral magnetic resonance refers to the use of a single coil to generate the $B_{0}$ field, as opposed to a pair. Single-sided magnetic resonance instruments have been widely used in the NMR community and are commercially available, such as the Magritek NMR Mouse [114]. The low-field EPR community dedicated to dosimetry and preclinical in vivo imaging has been at the forefront of development of a similar single-sided EPR assembly [19-21]. Unilateral magnetic resonance has used one of three different $B_{0}$ approaches, a close fringe field, a barrel magnet with a sweet spot, or a Halbach array. The fringe field design was used by Bluemich with the NMR-MOUSE (Mobile Universal Explorer) and has a very close active region with higher field inhomogeneity. The barrel magnet design uses the combination of two magnets to create a "sweet spot" of field strength and homogeneity at distances on the order of $30 \mathrm{~mm}$ from the surface of the magnet [115]. Halbach arrays have been used both to provide the typical 
bilateral $B_{0}$ in portable form factors (i.e., the "NMR-Cuff") [116] and have recently been employed in unilateral designs $[117,118]$.

\subsection{A Well-Established In situ Magnetic Resonance: Bore-Hole NMR}

Bore-hole NMR, a method in which spins in liquids contained within the porous rock wall of the bore are detected from an instrument inside the bore, has been in development since the early 1950s and is widely accepted as the tool for determining the presence of oil and the permeability of oil-containing rocks based on differences in proton relaxation times and signal amplitude [119]. The first patent for Earth's field NMR well logging was filed by Russell Varian in 1952 [120] followed by similar patents from Schlumberger in 1954. The first commercially available inside-out bore-hole NMR debuted in the early 1960s, and several companies followed suit. Early designs which depended on use of the Earth's field as the $B_{0}$ field fell short of expectations garnering a bad reputation in the industry. Inside-out pulse NMR using a magnetic field generated by magnets which were a part of the system was first demonstrated at Los Alamos National Laboratory (LANL) [121], and since has become a staple in the oil field. The technique continues to be improved, with many innovations coming from Schlumberger. In 2000, Schlumberger introduced a down-bore-hole NMR which functions simultaneously behind the drilling bit as it bores down into the earth. Down-bore hole NMR is a field unto itself, and several good reviews have been written [115, 119, 121].

The bore-hole environment in which the down-hole NMR operates is austere. Boreholes to extract oil are $20 \mathrm{~cm}$ in diameter and extend 1-10 km into the Earth [122]. Geothermal gradients can range up to $175 \mathrm{C}$, and pressures can reach $140 \mathrm{MPa}$ in these bore-holes. In addition, well-logging tools must survive transport in arctic, tropical and marine environments and survive shock up to $100 \mathrm{G}$ [121]. The down-bore NMR probe must survive the vibration and abrasion along rough, freshly cored rock as it is moved down the bore-hole. For down-bore hole NMR "the requirements for electronics components exceed military specifications by a wide margin" [121].

The information acquired from down-bore NMR includes characterization of pore structure in the subsurface rock, determination of fluid type (natural gas, petroleum or ground water) and permeability. Determination of porosity and liquid type is driven by grain-surface relaxation. Collisions of the protons with the grain surface of the pore result in relaxation in both $T_{1}$ and $T_{2}$ and are dependent on how often the collisions occur. Collisions are more frequent in smaller-sized pores (shorter relaxation) and less frequent in larger-sized pores (longer relaxation) and form the basis of differentiation of pore distribution sizes. Down-bore-hole NMR is an important example of the use of relaxometry as opposed to spectroscopy in spectrometer design.

\subsection{Low Field, In a Field: DOE ROOTS MRI}

Development of low-field MRI $(6.5 \mathrm{mT})$ has been driven in the last 10 years by the Department of Defense (DoD) and most recently by the Department of Energy (DoE). The DoE Advanced Research Projects Agency (ARPA-E) funds cutting edge technology advancements to tackle large-scale problems. Launched 
in 2016, ARPA-E's rhizosphere observations optimizing terrestrial sequestration (ROOTS) program targets the development of advanced technologies to enable an increase in soil $\mathrm{CO}_{2}$ accumulation in an effort to offset greenhouse emission [123]. One of the awarded projects is co-led by Cristine Morgan at Texas A\&M University (now Chief Scientific Officer at the Soil Health Institute) and Matthew Rosen of Massachusetts General Hospital (MGH) Martinos Imaging Center with support by ABQMR, Inc. and NIST-Boulder. The goal of the ROOTS project is to connect the phenotype of the root structure, while it is in the ground to the genes necessary to control how far the roots penetrate into the earth [124]. This information would in turn be used to direct roots to grow deeper into the ground, whereby carbon dioxide from the air could be more efficiently sequestered into the earth.

Simply digging the plant up and measuring the roots out of their natural environment-something akin to measuring the function of a skeleton without the adjacent organs or muscle mass-does not provide an accurate observation of root structure in situ. In addition, destructive sampling is inconsistent with timedependent measurements of plant development. The solution to this problem is in-ground magnetic resonance imaging (MRI), made possible by cutting edge image processing and a thorough knowledge of magnet design developed through non-traditional applications.

Rosen has pioneered, and continues to refine, collections of quality MRI acquired quickly at $6.5 \mathrm{mT}\left(275 \mathrm{kHz},{ }^{1} \mathrm{H}\right)$ originally developed for Army field hospitals [125]. To achieve this Rosen and his team had to breakdown how MRI is conventionally performed and re-invent instrumentation for use at low field. The work on the $6.5 \mathrm{mT}$ MRI instrument contributed to the early development of a new portable MRI scanner by Hyperfine Research Inc., co-founded by Rosen, Ron Walsworth at Harvard, and serial entrepreneur Jonathan Rothberg in 2014. Hyperfine Inc. subsequently developed their own bedside MRI scanner, introduced formally at the American College of Emergency Physicians meeting in Denver during October 2019 [126]. The scanner complements high-field MRI by offering MRI in a form which can be used as a triage tool in emergency situations. This new technology has been enlisted in the ongoing COVID-19 epidemic, as it has allowed MRI at $64 \mathrm{mT}$ to be completed on patients in the emergency rooms, rather than trying to move a critically ill and highly contagious patient to the high-field MRI suite [127].

The ROOTS project is only the latest example in a long history of in situ magnetic resonance experiments at $A B Q M R$. In what has to be a record for mobile resonant probe dimensions, the ABQMR team previously constructed an 18-foot diameter gradiometer coil which could be repositioned by a helicopter to make measurements using low-field NMR [128]. ABQMR was approached by members of the petroleum industry with a challenge to detect oil beneath ice floating on top of seawater using low-field NMR, a problem closely related to those targeted within the ROOTS program. Because this instrument operated in Earth's magnetic field where $B_{1}$ is comparable to or greater than $B_{0}$ (where the rotating field approximation fails) an inversion recovery sequence was developed by ABQMR to work in pre-polarization fields [129, 130]. 


\section{New Technology and Old Questions}

Electronics useful for low-field EPR experiments are well developed in the midto high hundreds of $\mathrm{MHz}$ driven by high-field NMR and MRI applications. Lowfield EPR applications may also draw from the advancements made in communications protocols, such as Long-Term Evolution (LTE, 0.4-5.9 GHz) and Bluetooth $(\sim 2.4 \mathrm{GHz})$, which has ushered the development of inexpensive, quality components with increasing commercial availability. As electronics improve, high-fidelity data may be collected much faster, leading to increases in SNR per unit time, such is in rapid-scan EPR.

In the rapid-scan experiment, the magnetic field is scanned much faster than the relaxation rate of spin system, resulting in transient responses in the resulting field swept spectrum (Fig. 3) [6]. The first observations of transient response "wiggles" in a magnetic resonance spectrum were in an NMR experiment where the field was swept at a rate fast relative to $T_{1}$ and $T_{2}$ [131]. It would be 56 years later that the Eaton laboratory at the University of Denver would characterize the oscillations of LiPc and the Nycomed trityl in the first rapid-scan EPR experiments at $250 \mathrm{MHz}$ [68]. Similar characterizations were performed in their laboratory at X-band before employing an entirely digital RS-EPR system with an AWG as the microwave source [132]. RS-EPR at DU has been expanded to imaging applications at $250 \mathrm{MHz}$, $700 \mathrm{MHz}$ and $1 \mathrm{GHz}$ in the Eaton laboratory, enabled by the ever-increasing availability of low-frequency microwave components. An entirely new EPR technique was born, in part by using new technology to answer old questions.

\subsection{Digital NMR}

As commercially available AWGs and digitizers have become less expensive and more user-friendly, constructing a low-field NMR instrument has become feasible for a wider variety of laboratories with varying levels of prior experience. Improved sampling rates, decreased source noise and larger microwave power output have enabled many purpose-built applications of digital NMR spectrometers, while faster digitizers with similarly improved sampling rates allow rapid and robust data acquisition [133]. Development of digital NMR has progressed quickly in the last 22 years. It began with construction of the first all-digital NMR spectrometer, operating at 30-250 kHz, from homebuilt circuit boards in 1998 [134]. Systems based on field-programmable gate array (FPGA) technology came into existence in 2007 $[135,136]$. Use of commercial peripheral component interconnect express (PCIe) cards resulted in several spectrometers being developed through mid-2015 [137, 138] including the low-field Overhauser Dynamic Nuclear Polarization Spectrometer constructed at NIST [106].

Recent advances in digital NMR have been driven by advances in softwaredefined radio technology (SDR). SDR was originally developed for cell phone services which process a variety of dynamic radio protocols in real time. Driven by demand to communicate ever faster, traditionally bulky, physical components of 


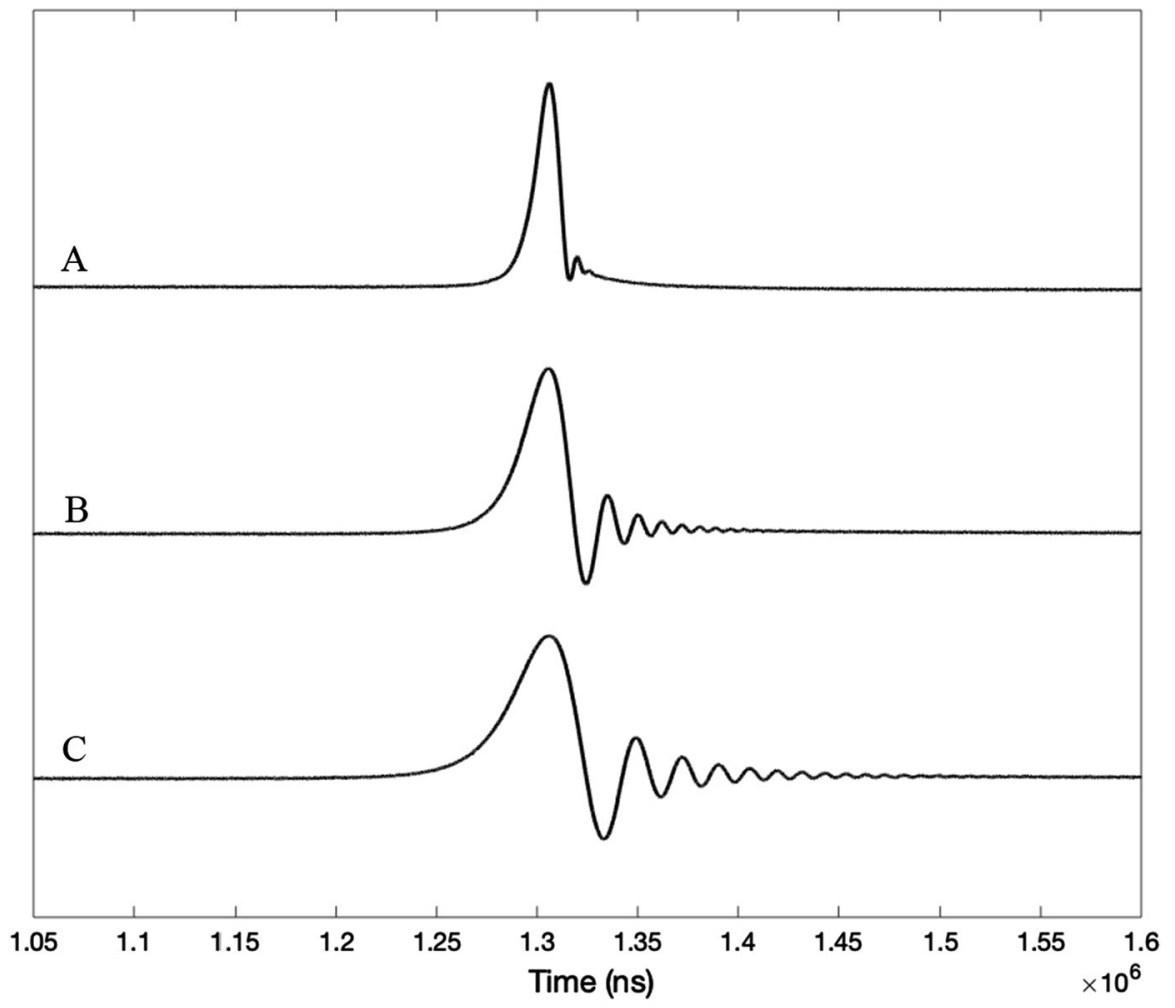

Fig. 3 Transient response observed in a rapid-scan EPR experiment. Data shown for a single particle of LiPc, recorded at X-band (ca. $9 \mathrm{GHz}$ ). a $11.8 \mathrm{~kg} / \mathrm{s}, \mathbf{b} 47.3 \mathrm{~kg} / \mathrm{s}, \mathbf{c} 80.2 \mathrm{~kg} / \mathrm{s}$

radio hardware - amplifiers, modulators, detectors, filters, mixers, etc.- are instead realized as miniaturized components in a single compact package. One example of this technology which is inexpensive $(\sim 300)$ and widely available is the LimeSDR which is about the size of a credit card. The original LimeSDR became available beginning in 2017 and has both transmit and receive functions from $100 \mathrm{kHz}$ to 3.8 GHz, which encompasses VHF, UHF, L-band (1-2 GHz) and much of S-band (2-4 GHz) for EPR experiments. As of 2018 a companion augmentation allowed the frequency range to be shifted for operation from $100 \mathrm{MHz}$ up to $10 \mathrm{GHz}$. Multiple LimeSDR cards can even be combined, as was done in 2018 by Michal and coworkers, to create a multi-channel SDR-based digital NMR console operating at $200 \mathrm{MHz}$ (4.7 $\mathrm{T}$ for $\left.{ }^{1} \mathrm{H}\right)$ [139].

\subsection{Digital EPR}

Digital excitation and detection technology for high magnetic field strengths have only recently been developed, as discussed in a recent perspective on the future of EPR [140]. In parallel, development of digital acquisition strategies at frequencies at 
or below $9.5 \mathrm{GHz}$ has been in development since the early 2000s. Direct detection of the EPR signal and the microwave carrier frequency at $2.5 \mathrm{GHz}$ were accomplished in 2004 with the aid of a very powerful (and expensive) digital oscilloscope [141]. Time-locked sub-sampling (TLSS) was developed by Hyde at the Medical College of Wisconsin (MCW) [142] but has not been widely incorporated due to the need for strict adherence to frequency values generating four samples in an odd number of cycles. The first direct digital detection of rapid-scan was performed at X-band in the Eaton laboratory at DU in 2014 [132]. The use of an AWG permitted downconversion to an intermediate detection frequency such that analog filters could be implemented to decrease non-EPR signals, as has been done successfully in other laboratories [132, 142-144]. Fully digital EPR for animal imaging has been implemented at $750 \mathrm{MHz}$ [145] and $1 \mathrm{GHz}$ [146], with automatic resonator tuning and matching, digital feedback control and digital automatic frequency control (digital AFC). Commercially available software packages (i.e., MATLAB, Specman4EPR [147]) can be configured to interface and connect various AWG and digitizers to facilitate digital EPR experiments making homebuilt instruments more accessible.

Electron relaxation times are on the order of ns to $\mu \mathrm{s}$, while nuclear relaxation times are on the order of ms to seconds-a difference of 3-9 orders of magnitude depending on which species are being compared. As a result, the required pulse timings for EPR relaxation experiments need to be about three orders of magnitude faster (ns vs $\mu \mathrm{s}$ ) than for nuclear relaxation experiments. Despite the faster timescales of electron relaxation, a recently published paper has demonstrated a 150MHz EPR spectrometer $\left(B_{0}=5 \mathrm{mT}\right)$ functioning in both $\mathrm{CW}$ and pulse mode based on a LimeSDR card [148]. For pulse mode a 6-turn solenoid, with a $10 \Omega$ resistor to lower the resonator $\mathrm{Q}$, was used to measure a 500-M $\mu$ Finland trityl sample $(20 \mathrm{mM}$ HEPES buffer, $\mathrm{pH} 7.2$ ) in a $130-\mu \mathrm{L}$ volume which corresponded to a calculated signal voltage of approximately $100 \mathrm{nV}$ and required $10^{5}$ averages for adequate SNR in FID measurements. The value of $T_{2}$ and $T_{1}$ for an oxygenated Finland trityl sample was $1.34 \mathrm{~s} \mu$ and $1.54 \mathrm{~s} \mu$, respectively.

The observable signal at $150 \mathrm{MHz}$ was recorded without the use of common low-field EPR approaches; sample size was not scaled up for low frequency, no advanced active circuit techniques were employed such as Q-spoiling in pulse EPR, and the experiment was done without the use of a bimodal resonator [5]. The isolation between excitation and detection modes of a bimodal resonator, together with Q-spoiling, was required for the collection of room temperature, fluid solution nitroxide relaxation data $(\sim 0.5-1 \mu \mathrm{s})$ using a traditional analog instrument [149]. The lowest time resolution employed was $33 \mathrm{~ns}$, but the authors stated that the SDR card was capable of time resolution down to $16 \mathrm{~ns}$.

CW-EPR measurements at $150 \mathrm{MHz}$ using the LimeSDR were also described. The 6-turn solenoid had a Q 90 without resistive Q-damping. A circuit was constructed such that the modulation coil could be driven by a phase coherent transistor-transistor logic (TTL) circuit from the LimeSDR. For the automated frequency control (AFC), a software-defined digital feedback circuit was implemented, an approach which has also been employed within the last year in an all-digital L-band spectrometer [146]. The AFC time window was set so that one frequency correction per data point was employed in a field sweep. 
There were various areas for improvement identified in both pulse and CW operation, mostly due to slow communication and frequent interruptions between the SDR card and the host laptop (connected via Universal Serial Bus, USB) selected for the experiments. The inability to achieve 16-ns time resolution was attributed in part to this problem. Newer revisions of the LimeSDR package are available that utilize faster USB protocols or a PCIe interface that may enable faster communication with fewer interruptions. The digital AFC implemented for $\mathrm{CW}$ was slow and introduced pronounced spikes in the $\mathrm{CW} B_{0}$-field sweeps visible near 45 and $53 \mathrm{G}$-though these artifacts were still orders of magnitude smaller than the signal from the trityl.

At $\$ 300$ for the SDR card, the addition of a laptop and supplies to build a coil enables the construction of an EPR spectrometer for $\sim \$ 1000$. Given the bandwidth of the LimeSDR card $(\sim 3.5 \mathrm{GHz})$, it is also potentially a multi-frequency microwave source and detector for an inexpensive price, though practically the source noise may limit operation to low frequencies $(<\sim 1 \mathrm{GHz})$ without the addition of a low noise fixed frequency source [77, 150]. This same card was programmed to perform NMR experiments, so that one unit could provide stand-alone DNP hardware using both transmit and receive channels on a single card. Aside from the use of DNP for the study of materials [102], this also means the instrument is able to perform DNP-detected EPR $[107,108]$.

\section{Examples of In situ Capable EPR}

In situ EPR has been used to describe high-field EPR studies of cells or small objects where the high resolution of EPR is exploited to study a single step (or multiple steps) in a larger multicomponent process or analysis. For example when used in electrochemical characterization of polymer electrolyte membranes [151], cobalt cathode chemistries are in lithium ion batteries [152] or graphene-based super-capacitors [153]. We define "In situ" as "in the original place"- - such as where the sample to be studied is naturally located in the physical world. It is unfortunate that a 4-mm quartz EPR tube does not seem to be the "original place" for most materials.

Traditionally EPR analysis has shied away from the type of in situ analysis typified at the extreme by down-bore-hole NMR. Down-bore-hole EPR for the study of vanadium species would be a valuable target in this regard [154], and along this vein, the field is moving toward a robust and diverse catalog of in situ applications. Four examples of different approaches which could form the foundation of in situ EPR are described in this section. Two approaches are based on the use of unilateral magnets and traditional resonant structure design, and two are based on non-resonant methods using interferometry and frequency-swept EPR. These methods have been employed at frequencies from $395 \mathrm{MHz}$ up to $14 \mathrm{GHz}$.

\subsection{Unilateral EPR: OxyChip}

The OxyChip is comprised of $40 \%$ (w/w) LiNc-BuO particles embedded in PDMS and is interrogated with a unilateral handheld EPR scanner [155]. The OxyChip was 
recently implanted under the skin of a rat model for 18 months and used to provide quantitative in vivo information on $\mathrm{pO}_{2}$ at the implantation site $[156,157]$. In the rat model, the PDMS-bound probe remained sensitive to oxygen and was unaffected by autoclaving or $80 \mathrm{~Gy}$ of X-ray irradiation, indicating it could be used in a clinical setting. A Phase I Clinical Trial enrolled its first patient in 2015 and is scheduled to end in 2020 [157].

Implantation of a robust, functional EPR probe in a bio-compatible polymer is only half the story. The other enabling technology is the novel single-sided EPR scanner for which a patent was awarded in 2017 [158]. Typical operating frequencies described are $2.4 \mathrm{GHz}$ for transcutaneous and $6.2 \mathrm{GHz}$ for subcutaneous analysis of the implanted butoxy probe. The main magnet is comprised of several commercially available Samarium-Cobalt hexahedron magnets $(4 \mathrm{~mm} \times 4 \mathrm{~mm} \times 8 \mathrm{~mm}$ ) in a Halbach array [155]. Nested inside the array, shielded in a thin layer of brass, is a copper loop-gap-resonator (LGR). The $B_{0}$ and resonator assembly are optimized for EPR analysis of a $0.5-\mathrm{mm}^{3}$ surface $\sim 3 \mathrm{~mm}$ from the assembly face with a field inhomogeneity of $<1000 \mathrm{ppm}$. The selection of a tiny active volume for analysis allows the $\pi / 2$ pulses to be powered with a small, solid-state $4 \mathrm{~W}$ amplifier.

The single-sided EPR scanner operates in pulse mode with $Q \sim 60$ for both subcutaneous and transcutaneous applications. The echo timing parameters described in the patent are optimized for observing relaxation times on the order of $1 \mu \mathrm{s}$. As an analytical tool, this instrument would be capable of measuring relaxation of trityl radicals and some nitroxide radicals if tumbling correlation times are slow enough and their molecular structure has been optimized to be compatible with transcutaneous and subcutaneous administration [149]. The current pulse set up would pose a difficulty for measurement of transition metal spectra at ambient temperatures due to their fast relaxation times.

\subsection{Unilateral EPR: The EPR-MOUSE}

Twenty-one years after Bluemich introduced the NMR-MOUSE, Hornak and his colleagues at the Rochester Institute of Technology constructed the EPR-MOUSE operating at $355 \mathrm{MHz}$ [159]. The spectrometer is based on a unilateral 2-pole yolk magnet combined with an electromagnet for field sweeping. Developed for analysis of large volumes at low field, it is immediately applicable to items and environments with cultural significance which cannot be destroyed during analysis. The yolk/electromagnet design was chosen over a Barrel magnet design because of the need to sweep the magnetic field specifically for analysis of broad signatures. A picture of the EPR-MOUSE is shown in Fig. 4 . The $B_{0}$ magnet and solenoid assembly weigh just over one pound.

Like the NMR-MOUSE, the EPR-MOUSE also has a very shallow active region parallel to the face. Sensitivity falls to $60 \%$ with only $0.25 \mathrm{~mm}$ stand-off, but the device has been designed to analyze samples pressed up against it. The use of the EPR-MOUSE for analysis of model paint samples was done by mixing four pigments (Ultramarine Blue, Rhodochrosite, Blue Vitriol and Terracotta Red) in Linseed oil and applying these to a single cardboard-backed canvas before analyzing 

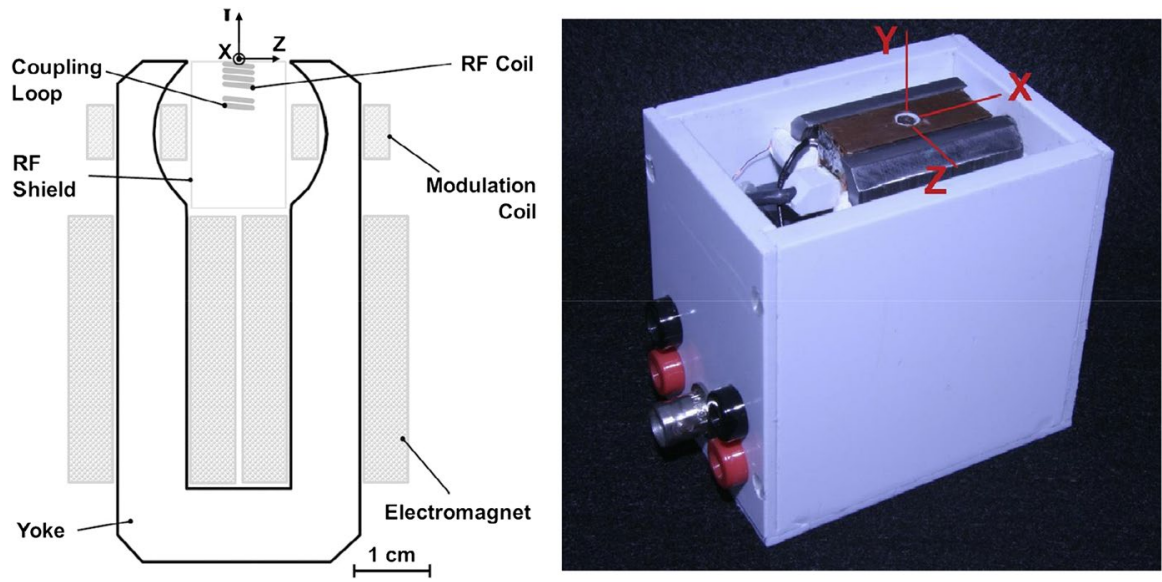

Fig. 4 The EPR MObile UniverSal Explorer (MOUSE) allows for samples to be placed directly on top of a unilateral $B_{0}$ assembly collocated with the $B_{1}$ resonator (solenoid). (Left) Schematic of the EPRMOUSE, (right) picture of the actual unit. Reproduced with permission from Ref. [160]

with the EPR-MOUSE. Despite each pigment having a very broad spectrum compared to the $45 \mathrm{mT}$ sweep width, all spectra recorded had sufficient SNR to differentiate pigments based on differences in g-factor and linewidth. The only pigment whose spectrum was too broad to be recorded over that range was rhodochrosite; however, the data fit well with a simulation of the EPR spectrum which extended beyond the $45 \mathrm{mT}$ sweep.

Plans to improve the $B_{0}$ active region and homogeneity include exploration of a 4-pole yolk and electromagnet in future work. Use of a barrel magnet would improve the analysis depth, $B_{0}$ homogeneity and size of the active region. A barrel magnet would require a different approach than traditional $\mathrm{CW}$, possibly through the use of frequency swept EPR rather than field swept, or even via development of a unilateral rapid-scan instrument. Alternatively, for samples with relaxation times of $\sim 1 \mu$ s and longer, pulse operation as described for analysis of the OxyChip combined with the EPR-MOUSE would be a powerful spectroscopic method. The important point is the demonstration of this form factor for EPR, which expands the technique to large and irregularly shaped objects and environments in a way that either the sample may be placed on top of the EPR-MOUSE or vice versa for in situ surface analysis.

\subsection{Non-Resonant EPR with an Interferometric Design}

In traditional EPR, coupling to the spin bath is done using any number of resonant structures. Some exceptions are common at high frequencies where the required physical dimensions of a resonant structure are impractical given the wavelength at the frequencies used [160]. Resonant structures greatly increase the experiment sensitivity by producing well-defined regions of B-field uniformity. This has led to an orthodoxy in EPR, that any attempts to use a non-resonant approach are a fool's errand, for surely the loss in sensitivity must be so great as to make the measurement 
"impossible." The use of resonant structures, specifically cavity resonant structures, can restrict the type and geometry of materials which can be analyzed, and in doing so handicap the EPR community's ability to branch out into completely new applications.

An excellent alternative to having to choose between either sensitivity or sample access was proposed recently in the form of a non-resonant transmission linebased interferometric EPR detection [161] scheme. This interferometric design was deployed with a classic bilateral $B_{0}$ field, but the interferometric EPR is agnostic of $B_{0}$ field generation and could be implemented as the basis of another example of unilateral EPR.

The interferometric EPR method was compared with a commercial X-band EPR spectrometer and high-quality resonator $(Q \sim 10,000)$ using $\gamma$-irradiated (190 Gy) fused quartz with field modulation, probe volume and modulation frequency held constant. Power saturation curves were completed for each method to ensure the final comparison was made at $B_{1}=0.4 \mu \mathrm{T}$ for the resonator-based EPR spectrometer and a saturation correlated equivalent of $B_{1}=0.09 \mu \mathrm{T}$ in the interferometric EPR spectrometer. The interferometric EPR method achieved SNR within a factor of two of the resonator-based spectrometers. The limits on multi-frequency uses of the interferometric technique are bound only by bridge components containing ferrites, such as mixers or circulators, which have an inherently narrow bandwidth. The interferometric EPR method has been implemented at $7.6 \mathrm{GHz}$ using a vector network analyzer (VNA) for detection [162], forming the basis of a spectrometer capable of measuring ferromagnetic resonance [163].

Interferometric approaches use a reference arm, but in a considerably different context than in traditional EPR spectrometers. In common commercial applications of CW-EPR, the reference arm exists to provide a bias voltage for proper crystal detector operation. In digital and other modern EPR applications, the reference arm is formed by a separate microwave input, providing the local oscillator for use with a double-balanced mixer as a phase-sensitive detector. In interferometric EPR, the reference arm is instead a form of background correction, and the instrument is tuned so that in the absence of the EPR signal the reference arm and sample path arm achieve near perfect destructive interference at a power combiner. The loss in Q-factor is nearly completely compensated by a 60-70 dB suppression of the background noise using this highly balanced interferometric design.

\subsection{Frequency Swept EPR “MR to Go"}

Building on the design characteristics highlighted by the LimeSDR spectrometer, applications of single-chip NMR and EPR spectrometers have been developed, achieving spin sensitivities of $\sim 10^{9}$ spins per $\sqrt{\mathrm{Hz}}$ when operating at $14 \mathrm{GHz}$ [164]. Efforts to minimize the MR spectrometer are summarized in the recent review by Anders and Lips [164]. Though most applications of in-field EPR utilize a slowly sweeping magnetic field while operating at a constant frequency, small frequencyswept EPR spectrometers have been developed using complementary metal-oxide semiconductor (CMOS) packages $[165,166]$. In frequency-swept experiments, the 
resonator becomes a problem due to the large bandwidth requirements of wide frequency sweeps. To use a high $\mathrm{Q}$ resonator without filtering in a frequency-swept experiment, the entire frequency sweep must either be contained within the narrow bandwidth of a critically coupled resonator, greatly limiting sweep width, or the resonator must dynamically and instantaneously change coupling to every frequency within the frequency sweep, greatly increasing the complexity of the experiment [164]. A solution to this problem is to instead use a voltage-controlled oscillator (VCO) inductively coupled to the sample such that the EPR signal may be realized as a change in the oscillating frequency as the frequency sweep passes through resonance $[165,167,168]$. This approach has now been utilized in a battery-operated portable EPR spectrometer intended for point-of-care (POC) applications in medicine $[166,169]$. Early attempts in incorporating VCOs into miniaturized EPR spectrometers were limited in sensitivity by small sample volumes; however, multiple VCOs, arranged in a single array, have recently been developed to greatly increase sample volumes, driving sensitivity to $200 \mu \mathrm{M}$ concentrations [170]. The current generation of VCO-based single-chip EPR spectrometers is very small $\left(<4 \mathrm{~mm}^{2}\right)$ and is well-suited for in situ operation.

\section{Discussion}

In a recent discussion of future directions in Quo Vadis EPR?, the observation is made that "lack of local expertise leads to under use of EPR spectroscopy, which in turn leads to the perception that it is not necessary to have local expertise" [140]. These, combined with constrained funding opportunities, are two proponents greatly inhibiting the development of EPR. In addition to these observations, a third limit on expansion of EPR is the notion that EPR instrumentation has to be large, bulky, expensive and confined to a laboratory setting. That idea is entrenched in some parts of the EPR community, and the inability to envision manifestations of EPR outside the laboratory only reinforces its perpetual underutilization.

The development of in-field and in situ uses for EPR is not confined to the domain of low field, as the single-chip efforts at $14 \mathrm{GHz}$ clearly demonstrate. The OxyChip portable spectrometer demonstrates use of low-field magnetic resonance in a "wand" form factor which is familiar to materials scientists and engineers accustomed to eddy current testing (ECT) or ultrasound inspection (UT). These are devices employed in the field, on the manufacturing floor, and in the service depot of different DoD branches. The EPR-MOUSE demonstrates a form factor which is useful both inside and outside the laboratory. For instance, large petroleum companies have dedicated laboratory support in addition to in-field magnetic resonance tools like down-bore NMR.

Issues of sensitivity in the low-field manifestations of in situ EPR are not clearcut, since the lower operating frequency can be offset by larger sample size and lowering the noise floor of the system. One issue for low-field in situ measurements which is not encountered in high-field in situ applications occurs for broad spectra and is illustrated in Hornak's EPR-MOUSE when analyzing the broad spectrum from Rhodochrosite $\left(\mathrm{MnCO}_{3}\right)$. The observed spectrum is a single broad peak due to dipolar 
coupling between $\mathrm{Mn}^{2+}$ ions with $g=3.849$. Acquiring the spectrum at $355 \mathrm{MHz}$ means recording the $B_{0}$ field from 0 to $38 \mathrm{mT}$, and over this range the total Rhodochrosite linewidth is only partially captured. The spectrum is confirmed with simulation of the lineshape which extends into both the negative and positive regions of $B_{0}$ where the spectrum exists. Of the four pigments with broad spectra assessed, only Ultramarine Blue is measured in its entirety at $355 \mathrm{MHz}$.

Another drawback to current widespread use of low-field EPR is the lack of commercially available spectrometers. Small-animal imaging systems are commercially available at $1 \mathrm{GHz}$ (Bruker' ELEXSYS-II E540) and $25 \mathrm{mT}$ (O2M's JIVA-25), as well as an add-on to a commercial X-band spectrometer which uses frequency mixing to down-convert the spectrometer to an operating range of 0.8-1.4 GHz (Bruker SuperLIFT). Several X-band benchtop EPR spectrometers are commercially available, and the benchtop format is an easy way to introduce EPR into new areas with scientists and engineers who have not previously been aware of its excellent capabilities. There are as of yet, no benchtop low-field/frequency $(\leq 4 \mathrm{GHz})$ commercial offerings. In order for a commercial benchtop low-frequency system to be developed, a number of key applications would have to be identified to determine what center frequency range would be offered. The different, but complimentary, information that can be acquired from the effect of g- and A-strain at low field and high field could be one of those applications.

In powders and glasses containing square planar copper complexes, extra line broadening observed was attributed to g- and A-strain by Hagen in 1980 [171] for copper metalloproteins at $20 \mathrm{~K}$ and later extended to ferredoxins [172]. In terms of the molecular orbital description, broadening arises from a distribution of bonding parameters because of the distribution of distinct ligand microenvironments for $\mathrm{Cu}^{2+}$. Under these conditions a different ligand-metal microenvironment results in a distribution of g-values overlapping one another, leading to line broadening. Selection of the correct sample orientation can highlight one subset of microenvironments over others, which is helpful in determining the ligand environment around the metal. While $20 \mathrm{~K}$ is not a temperature regime commonly employed in in situ environments explored to date, the g-strain has also been used to explain spectral features of $\mathrm{Cu}^{2+}$ doped zeolites at room temperature [173]

Around the same time g-strain was being used to explain extra line broadening at high field, Froncisz and Hyde noted at low field the presence of "turning points" in the g-parallel region of derivative spectra from square planar copper complexes is identical to pure absorption spectra from single crystals in the parallel orientation [174]. At these turning points, the g-strain and A-strain are correlated, and the correlation was parameterized by introduction of the term $\varepsilon$. The g- and A-strain tended to cancel at $M_{\mathrm{I}}=-1 / 2$ and $M_{\mathrm{I}}=-3 / 2$ and added together for $M_{\mathrm{I}}=+1 / 2$ and $M_{\mathrm{I}}=+3 / 2$. That is, depending on the values of $\mathrm{g}$ - and A-strain, a low frequency exists where g- and A-strain-induced inhomogeneous broadening cancels out, and the hyperfine information for nitrogen containing ligands on the copper atom becomes more easily discernable.

The collapsing of g- and A-strain components at low-field was invoked in a series of papers investigating binding in prion proteins [175] at a frequency of $3 \mathrm{GHz}$. Due to the addition or cancellation of $g$ - and A-strain at this frequency, 0, 1, 2 or 3 
nitrogen ligands bound to the copper center could be distinguished. In 2009, a model copper histidine with 4 nitrogen ligands bound was detailed [176]. In that report an even lower frequency of $2 \mathrm{GHz}$ was used. The studies at $3 \mathrm{GHz}$ had shown that the highest resolution in terms of hyperfine information was found in the g-parallel region at $M_{\mathrm{I}}=-1 / 2$. However, at $2 \mathrm{GHz}$ this changed, with the highest resolution attributed to the $\mathrm{g}$-perpendicular region at $M_{\mathrm{I}}=+1 / 2$.

The multi-frequency interpretation of g- and A-strain is likely a nexus around which developing both low- and high-field techniques, and both in situ and laboratory techniques can proceed in a synergistic way. Knowledge of metal centers in different microenvironments is a key part of understanding not only metalloproteins, but also zeolites and metal-organic framework (MOFs) [177], which are inspired by the natural design of the zeolite. In turn, new knowledge of the ligand environment in the wide variety of MOF structures that can be synthesized may aid interpretation of metalloprotein binding in biological settings.

\section{Summary}

This review article celebrates the 80th birthday of Gareth Eaton, and in recognition of the work both he and Sandra Eaton have done in support of the advancement of EPR. In addition to recognition of published works and the development of rapidscan, the review also aimed to capture a sense of forward-looking imagination for what EPR can be, in addition to all the wonderful things it is currently.

In his article entitled "Low Fields but High Impact: Ex-Situ NMR and MRI," Yi-Qiao Song declared there is "plenty of room at the bottom" and that widespread use of magnetic resonance technology in general can be facilitated widely by inexpensive electronics and magnet designs at low-field" [178]. The same argument can also be made for EPR, and some examples have been given in this review. That this review focuses on the Eatons' work in the low-field is not to dismiss a long record of accomplishments elsewhere in the world of EPR, nor is it an argument for low-field EPR instead of high-field EPR. Rather this review imagines further development of low-field EPR as a compliment to high-field EPR. The two regimes together will propel the entire field forward further than either can alone.

Acknowledgements This review compiles a few of the numerous contributions from multiple disciplines, all under the broad umbrella of magnetic resonance. The authors would like to thank Matt Rosen (University of Massachusetts General Hospital), Eiichi Fukushima (ABQMR, Inc.) and Jason Campbell (NIST) for early comments on this manuscript. We thank two anonymous reviewers for their insight. We especially appreciate the commentary of one reviewer which set us on the path of multi-frequency manifestations of g- and A-strain.

\section{References}

1. S.S. Eaton, G.R. Eaton, J. Magn. Reson. 223, 151-163 (2012)

2. G.A. Rinard, R.W. Ouine, G.R. Eaton, S.S. Eaton, E.D. Barth, C.A. Pelizzari et al., Concepts Magn. Reson. 15, 51-58 (2002)

3. R.W. Ouine, G.A. Rinard, S.S. Eaton, G.R. Eaton, Concepts Magn. Reson. 15, 59-91 (2002) 
4. G.A. Rinard, R.W. Quine, B.T. Ghim, S.S. Eaton, G.R. Eaton, J. Magn. Reson. Ser. A 122, 50-57 (1996)

5. G.A. Rinard, R.W. Ouine, G.R. Eaton, S.S. Eaton, Concepts Magn. Reson. 15, 37-46 (2002)

6. G.R. Eaton, S.S. Eaton, Rapid-scan EPR, in EPR Spectroscopy: Fundamentals and Methods. ed. by D. Goldfarb, S. Stoll (Wiley, UK, 2018), pp. 503-520

7. S.R. Burks, M.A. Bakhshai, M.A. Makowsky, S. Muralidharan, P. Tsai, G.M. Rosen, J.Y. Kao, J. Org. Chem. 75, 6463-6467 (2010)

8. S.R. Burks, M.A. Makowsky, Z.A. Yaffe, C. Hoggle, P. Tsai, S. Muralidharan, M.K. Bowman, J.P.Y. Kao, G.M. Rosen, J. Org. Chem. 75, 4737-4741 (2010)

9. S.R. Burks, L.F. Macedo, E.D. Barth, K.H. Tkaczuk, S.S. Martin, G.M. Rosen et al., Breast Cancer Res. Treat. 124, 121-131 (2010)

10. S.R. Burks, E.D. Barth, H.J. Halpern, G.M. Rosen, J.P.Y. Kao, Biochim. Biophys. Acta 1788, 2301-2308 (2009)

11. J.P.Y. Kao, E.D. Barth, S.R. Burks, P. Smithback, C. Mailer, K.H. Ahn et al., Magn. Reson. Med. 58, 850-854 (2007)

12. G.M. Rosen, S.R. Burks, M.J. Kohr, J.P.Y. Kao, Org. Biomol. Chem. 3, 645-648 (2005)

13. W. Takahashi, A.A. Bobko, I. Dhimitruka, H. Hirata, J.L. Zweier, A. Samouilov et al., Appl. Magn. Reson. 45, 817-826 (2014)

14. A. Samouilov, O.V. Efimoya, A.A. Bobko, Z. Sun, S. Petryakov, T.D. Eubank et al., Anal. Chem. 86, 1045-1052 (2014)

15. I. Dhimitruka, M. Velayutham, A.A. Bobko, V.V. Khramtsov, F.A. Villamena, C.M. Hadad et al., Bioorg. Med. Chem. Lett. 17, 6801-6805 (2007)

16. P. Kuppusamy, H.Q. Li, G. Ilangovan, A.J. Cardounel, J.L. Zweier, K. Yamada et al., Cancer Res. 62, 307-312 (2002)

17. S.S. Velan, R.G.S. Spencer, J.L. Zweier, P. Kuppusamy, Magn. Reson. Med. 43, 804-809 (2000)

18. P. Kuppusamy, M. Afeworki, R.A. Shankar, D. Coffin, M.C. Krishna, S.M. Hahn, B. Mitchell, J.L. Zweier, Can. Res. 58, 15662-15680 (1998)

19. H.M. Swartz, A.B. Flood, B.B. Williams, R. Dong, S.G. Swarts, X. He et al., Health Phys. 103, 255-267 (2012)

20. B.B. Williams, A. Sucheta, R. Dong, Y. Sakata, A. Iwasaki, G. Burke et al., Radiat. Measure. 42, 1094-1098 (2007)

21. H.M. Swartz, A. Iwasaki, T. Walczak, E. Demidenko, I. Salikov, P. Lesniewski et al., Appl. Radiat. Isotopes 62, 293-299 (2005)

22. B. Gallez, K. Mader, H.M. Swartz, Magn. Reson. Med. 36, 694-697 (1996)

23. J.J. Eckburg, J.C. Chato, K.J. Liu, M.W. Grinstaff, H.M. Swartz, K.S. Suslick et al., J. Biomech. Eng. 118, 193-200 (1996)

24. B. Epel, M.C. Maggio, E.D. Barth, R.C. Miller, C.A. Pelizzari, M. Krzykawska-Serda et al., Int. J. Radiat. Oncol. Biol. Phys. 103, 977-984 (2019)

25. B. Epel, M. Kotecha, H.J. Halpern, J. Magn. Reson. 280, 149-157 (2017)

26. S.V. Sundramoorthy, B. Epel, H.J. Halpern, Appl. Magn. Reson. 48, 805-811 (2017)

27. B. Epel, H.J. Halpern, J. Magn. Reson. 254, 56-61 (2015)

28. G. Redler, B. Epel, H.J. Halpern, Concepts Magn. Reson. Part B Magn. Reson. Eng. 45, 33-45 (2015)

29. G. Redler, Z.W. Qiao, B. Epel, H.J. Halpern, Concepts Magn. Reson. Part B Magn. Reson. Eng. 45, 46-57 (2015)

30. B.Epel, S.V. Sundramoorthy, M. Krzykowska-Serda, M. Maggio, M. Tseytlin, V.K. Khramtsov, G.R. Eaton, G.M.Rosen, J.P. Kao, H.J. Halper in Proceedings of the 57th Rocky Mountain Conference on Magnetic Resonance (Snowbird, Utah, 26-31 July 2015) Poster \#209

31. S.V. Sundramoorthy, B. Epel, H.J. Halpern, J. Magn. Reson. 240, 45-51 (2014)

32. B. Epel, M.K. Bowman, C. Mailer, H.J. Halpern, Magn. Reson. Med. 72, 362-368 (2014)

33. G. Redler, E.D. Barth, K.S. Bauer, J.P.Y. Kao, G.M. Rosen, H.J. Halpern, Magn. Reson. Med. 71, 1650-1656 (2014)

34. B. Epel, G. Redler, H.J. Halpern, in Oxygen Transport to Tissue Xxxvi, vol. 812, ed. by H.M. Swartz, D.K. Harrison, D.F. Bruley (Springer Open, 2014) pp. 113-119

35. G. Redler, B. Epel, H.J. Halpern, in Oxygen Transport to Tissue Xxxvi, vol. 812, ed. by H.M. Swartz, D.K. Harrison, D.F. Bruley (Springer Open 2014) pp. 121-126

36. G. Redler, B. Epel, H.J. Halpern, in Oxygen Transport to Tissue Xxxvi, vol. 812, ed. by H.M. Swartz, D.K. Harrison, D.F. Bruley (Springer Open 2014) pp. 127-133 
37. G. Redler, B. Epel, H.J. Halpern, Magn. Reson. Med. 71, 440-450 (2014)

38. B. Epel, M.K. Bowman, C. Mailer, H.J. Halpern, Magn. Reson. Med. 72, 362-368 (2014)

39. M. Elas, J.M. Magwood, B. Butler, C. Li, R. Wardak, E.D. Barth et al., Can. Res. 73, 5328-5335 (2013)

40. G. Redler, M. Elas, B. Epel, E. D. Barth, H. J. Halpern, in Oxygen Transport to Tissue Xxxv. ed. by S. Van Huffel, G. Naulaers, A. Caicedo, D.F. Bruley, D.K. Harrison (Springer, New York, 2013) pp. 399-404

41. G. Redler, E.D. Barth, K.S. Bauer, J.P.Y. Kao, G.M. Rosen, H.J. Halpern, Magn. Reson. Med. 71, 1650-1656 (2013)

42. B. Epel, S.V. Sundramoorthy, H.J. Halpern, Concepts Magn. Reson. Part B Magn. Reson. Eng. 39B, 167-172 (2011)

43. L. Lampp, O.Y. Rogozhnikova, D.V. Trukhin, V.M. Tormyshev, M.K. Bowman, N. Devasahayam et al., Free Radic. Biol. Med. 130, 120-127 (2019)

44. K.I. Matsumoto, J.B. Mitchell, M.C. Krishna, Free Radic. Res. 52, 248-255 (2018)

45. H. Jang, S. Matsumoto, N. Devasahayam, S. Subramanian, J.C. Zhuo, M.C. Krishna et al., Magn. Reson. Med. 73, 1692-1701 (2015)

46. Y. Takakusagi, S. Matsumoto, K. Saito, M. Matsuo, S. Kishimoto, J.W. Wojtkowiak et al., Plos One 9, e107995 (2014)

47. A. Enomoto, H. Hirata, S. Matsumoto, K. Saito, S. Subramanian, M.C. Krishna et al., Magn. Reson. Med. 71, 853-858 (2014)

48. S. Subramanian, N. Devasahayam, S. Matsumoto, K. Saito, J.B. Mitchell, M.C. Krishna, J. Magn. Reson. 218, 105-114 (2012)

49. M.C. Krishna, S. Matsumoto, H. Yasui, K. Saito, N. Devasahayam, S. Subramanian et al., Radiat. Res. 177, 376-386 (2012)

50. S. Subramanian, N. Devasahayam, A. McMillan, S. Matsumoto, J.P. Munasinghe, K. Saito et al., J. Magn. Reson. 214, 244-251 (2012)

51. H. Yasui, S. Matsumoto, N. Devasahayam, J.P. Munasinghe, R. Choudhuri, K. Saito et al., Can. Res. 70, 6427-6436 (2010)

52. O. Tseytlin, P. Guggilapu, A.A. Bobko, H. AlAhmad, X. Xu, B. Epel et al., J. Magn. Reson. 305, 94-103 (2019)

53. M. Poncelet, B. Driesschaert, O. Tseytlin, M. Tseytlin, T.D. Eubank, V.V. Khramtsov, Bioorg. Med. Chem. Lett. 29, 1756-1760 (2019)

54. U. Sanzhaeva, X. Xu, P. Guggilapu, M. Tseytlin, V.V. Khramtsov, B. Driesschaert, Angew. Chem. Intern. Edn. 57, 11701-11705 (2018)

55. V.V. Khramtsov, A.A. Bobko, M. Tseytlin, B. Driesschaert, Anal. Chem. 89, 4758-4771 (2017)

56. B.T. Ghim, S.S. Eaton, G.R. Eaton, R.W. Quine, G.A. Rinard, S. Pfenninger, J. Magn. Reson. Ser. A 115, 230-235 (1995)

57. R.W. Quine, G.A. Rinard, B.T. Ghim, S.S. Eaton, G.R. Eaton, Rev. Sci. Instrum. 67, 2514-2527 (1996)

58. G.R. Eaton, S.S. Eaton, D.P. Barr, R.T. Weber, Quantitative EPR (Springer, Wien, 2010).

59. G.A. Rinard, R.W. Quine, J.R. Harbridge, R.T. Song, G.R. Eaton, S.S. Eaton, J. Magn. Reson. 140, 218-227 (1999)

60. G.A. Rinard, R.W. Quine, R.T. Song, G.R. Eaton, S.S. Eaton, J. Magn. Reson. 140, 69-83 (1999)

61. G.A. Rinard, R.W. Quine, S.S. Eaton, G.R. Eaton, J. Magn. Reson. 154, 80-84 (2002)

62. G.A. Rinard, R.W. Quine, S. Eaton, G.R. Eaton, J. Magn. Reson. 156, 113-121 (2002)

63. L.A. Buchanan, L.B. Woodcock, R.W. Quine, G.A. Rinard, S.S. Eaton, G.R. Eaton, J. Magn. Reson. 293, 1-8 (2018)

64. R.W. Quine, G.A. Rinard, S.S. Eaton, G.R. Eaton, J. Magn. Reson. 205, 23-27 (2010)

65. M. Tseitlin, R.W. Quine, G.A. Rinard, S.S. Eaton, G.R. Eaton, J. Magn. Reson. 203, 305-310 (2010)

66. M. Tseitlin, T. Czechowski, R.W. Quine, S.S. Eaton, G.R. Eaton, J. Magn. Reson. 196, 48-53 (2009)

67. J.P. Joshi, J.R. Ballard, G.A. Rinard, R.W. Quine, S.S. Eaton, G.R. Eaton, J. Magn. Reson. 175, 44-51 (2005)

68. J.W. Stoner, D. Szymanski, S.S. Eaton, R.W. Quine, G.A. Rinard, G.R. Eaton, J. Magn. Reson. 170, 127-135 (2004)

69. J.R. Harbridge, G.A. Rinard, R.W. Quine, S.S. Eaton, G.R. Eaton, J. Magn. Reson. 156, 41-51 (2002) 
70. D.G. Mitchell, M. Tseitlin, R.W. Quine, V. Meyer, M.E. Newton, A. Schnegg et al., Mol. Phys. 111, 2664-2673 (2013)

71. D.G. Mitchell, R.W. Quine, M. Tseitlin, V. Meyer, S.S. Eaton, G.R. Eaton, Radiat. Meas. 46, 993996 (2011)

72. D.G. Mitchell, G.M. Rosen, M. Tseitlin, B. Symmes, S.S. Eaton, G.R. Eaton, Biophys. J. 105, 338-342 (2013)

73. Z.L. Yu, R.W. Quine, G.A. Rinard, M. Tseitlin, H. Elajaili, V. Kathirvelu et al., J. Magn. Reson. 247, 67-71 (2014)

74. Z. Yu, T. Liu, H. Elajaili, G.A. Rinard, S.S. Eaton, G.R. Eaton, J. Magn. Reson. 258, 58-64 (2015)

75. J.R. Biller, M. Tseitlin, D.G. Mitchell, Z.L. Yu, L.A. Buchanan, H. Elajaili et al., Chem. Phys. Chem. 16, 528-531 (2015)

76. J.R. Biller, M. Tseitlin, R.W. Quine, G.A. Rinard, H.A. Weismiller, H. Elajaili et al., J. Magn. Reson. 242, 162-168 (2014)

77. L.A. Buchanan, G.A. Rinard, R.W. Quine, S.S. Eaton, G.R. Eaton, Concepts Magn. Reson. Part B Magn. Reson. Eng. 48B, e21384 (2018)

78. H. Elajaili, Biller, J.R., Rosen, G.M., Kao, J.P.Y., Tseytlin, M., Buchanan, L.B., Rinard, G.A., Quine, R.W., McPeak, J., Shi, Y., Eaton, S.S., Eaton, G.R., J. Magn. Reson. (2015)

79. Y. Shi, S.S. Eaton, G.R. Eaton, J. Magn. Reson. 308, 106593 (2019)

80. D. Goldfarb, S. Stoll, EPR Spectroscpy: Fundamentals and Methods (Wiley, USA, 2018).

81. A. Serra-Valls, C. Gago-Bousquet, M. García-Sucre, Phys. Rev. B. 9, 4667-4672 (1974)

82. D.T. Petasis, M.P. Hendrich, Methods Enzymol. 563, 171-208 (2015)

83. M.S. Fataftah, J.M. Zadrozny, S.C. Coste, M.J. Graham, D.M. Rogers, D.E. Freedman, J. Am. Chem. Soc. 138, 1344-1348 (2016)

84. S. Bertaina, G. Yue, C.E. Dutoit, I. Chiorescu, Phys. Rev. B. 96, 024428 (2017)

85. M. Kaushik, T. Bahrenberg, T.V. Can, M.A. Caporini, R. Silvers, J. Heiliger et al., Phys. Chem. Chem. Phys. 18, 27205-27218 (2016)

86. J.S. Hyde, R.A.Strangeway, T.G. Camenisch, J.W. Sidabras, R. R. Mett, G.A. Rinard, R.Q. Quine, S.S. Eaton, G.R. Eaton, in Multifrequency EPR: Theory and Applications, ed. by M. Krishna (Wiley-VCH Verlag GmBH \& Co., Weinheim, 2011) pp. 229-294

87. J.R. Pilbrow, Transition Ion Electron Paramagnetic Resonance (Clarendon Press, Oxford, 1990)

88. M.M. Roessler, M.S. King, A.J. Robinson, F.A. Armstrong, J. Harmer, J. Hirst, Proc. Natl. Acad. Sci. USA 107, 1930-1935 (2010)

89. S. Stoll, A. Schweiger, J. Magn. Reson. 178, 42-55 (2006)

90. A.W. Kittell, T.G. Camenisch, J.J. Ratke, J.W. Sidabras, J.S. Hyde, J. Magn. Reson. 211, 228-233 (2011)

91. J.S. Hyde, B. Bennett, A.W. Kittell, J.M. Kowalski, J.W. Sidabras, J. Magn. Reson. 236, 15-25 (2013)

92. D.J. McCrory, M.A. Anders, J.T. Ryan, P.R. Shrestha, K.P. Cheung, P.M. Lenahan et al., Rev. Sci. Instrum. 90, 014708 (2019)

93. M. Tseitlin, G.A. Rinard, R.W. Quine, S.S. Eaton, G.R. Eaton, J. Magn. Reson. 211, 156-161 (2011)

94. J.R. Biller, D.G. Mitchell, M. Tseytlin, H. Elajaili, G.A. Rinard, R.W. Quine et al., J. Vis. Exp. (115) e54068, https://doi.org/10.3791/54068 (2016)

95. M. Bennati, in EPR spectroscopy: Fundamentals and Methods, ed. by D. Goldfarb, S. Stoll (Wiley, UK, 2018) pp. 81-94

96. R. Owenius, M. Engström, M. Lindgren, M. Huber, J. Phys. Chem. A. 105, 10967-10977 (2001)

97. D. Marsh, Appl. Magn. Reson. 37, 435-454 (2010)

98. A.A. Bobko, T.D. Eubank, J.L. Voorhees, O.V. Efimova, I.A. Kirilyuk, S. Petryakov et al., Magn. Reson. Med. 67, 1827-1836 (2012)

99. S. Koda, J. Goodwin, V.V. Khramtsov, H. Fujii, H. Hirata, Anal. Chem. 84, 3833-3837 (2012)

100. J.S. Hwang, R.P. Mason, L.-P. Hwang, J.H. Freed, J. Phys. Chem. 79, 489-511 (1975)

101. S.K. Buchanan, G.C. Dismukes, Biochemistry 26, 5049-5055 (1987)

102. J.R. Biller, R. Barnes, S. Han, Curr. Opin. Colloid Interface Sci. 33, 72-85 (2018)

103. D.J. Lurie, I. Nicholson, J.S. McLay, J.R. Mallard, Appl. Magn. Reson. 3, 917-925 (1992)

104. T. Guiberteau, D. Grucker, Phys. Med. Biol. 43, 1887-1892 (1998)

105. J. R. Biller, J. McPeak, S. S. Eaton, G. R. Eaton, Appl. Magn. Reson. 49, 1235-1251 (2018)

106. J.R. Biller, K.F. Stupic, J.M. Moreland, Magn. Reson. Chem. 56, 153-163 (2018)

107. D.J. Lurie, J.S. McLay, I. Nicholson, J.R. Mallard, J. Magn. Reson 95, 405-409 (1991) 
108. D.J. Lurie, I. Nicholson, J.R. Mallard, J. Magn. Reson. 94, 197-203 (1991)

109. C. Polyon, D.J. Lurie, W. Youngdee, C. Thomas, I. Thomas, J. Phys. D-Appl. Phys. 40, 5527-5532 (2007)

110. D. Grucker, T. Guiberteau, G. Planinsic, Res. Chem. Intermed. 22, 567-579 (1996)

111. T. Guiberteau, D. Grucker, J. Magn. Reson. B 110, 47-54 (1996)

112. T. Guiberteau, D. Grucker, J. Magn. Reson. A 105, 98-103 (1993)

113. G. Eidmann, R. Savelsberg, P. Blumler, B. Blumich, J. Magn. Reson. A 122, 104-109 (1996)

114. Magritek (08-04-20). NMR Mouse. Available: https://magritek.com/products/nmr-mouse/

115. S. Utsuzawa, E. Fukushima, J. Magn. Reson. 282, 104-113 (2017)

116. C.W. Windt, H. Soltner, D. van Dusschoten, P. Blumler, J. Magn. Reson. 208, 27-33 (2011)

117. W.-H. Chang, J.-H. Chen, L.-P. Hwang, Magn. Reson. Imaging 24, 1095-1102 (2006)

118. A. Bashyam, M. Li, M.J. Cima, J. Magn. Reson. 292, 36-43 (2018)

119. D.E. Woessner, Concepts Magn. Reson. 13, 77-102 (2001)

120. R. H. Varian, Apparatus and Method for Identifying Substances. United States Patent (1952)

121. R.J.S. Brown, R. Chandler, J.A. Jackson, R. Kleinberg, M.N. Miller, Z. Paltiel et al., Concepts Magn. Reson. 13, 335-413 (2001)

122. T. Ma, P. Chen, J. Zhao, Geomech. Geophys. Geo-Energy Geo-Resour. 2, 365-395 (2016)

123. D. Babson, Rhizosphere Observations Optimizing Terrestrial Sequestration. (Advanced Research Projects Agency - Energy, 2016). https://arpae.energy.gov/technologies/programs/ roots

124. G.C. Bagnall, N. Koonjoo, S.A. Altobelli, M.S. Conradi, E. Fukushima, D.O. Kuethe et al., J. Soil 370, $114356(2020)$

125. M. Sarracanie, C. D. LaPierre, N. Salameh, D.E.J. Waddington, T. Witzel, M.S. Rosen, Sci. Rep. 5, 15177 (2015)

126. O. Kaye-Kauderer, Hyperfine Introduces World's First Point-of-Care MRI System at the American College of Emergency Physicians (ACEP) Scientific Assembly 2019. Available: https://www.businesswire.com/news/home/20191028005588/en/Hyperfine-Introduces-World $\%$ E2\% 80\%99s-Point-of-Care-MRI-System-American (2019)

127. K.N. Sheth, M.H. Mazurek, M.M. Yuen, B.A. Cahn, J.T. Shah, A. Ward et al., JAMA Neurol. 78(1), 41-47 (2020)

128. S.A. Altobelli, M.S. Conradi, E. Fukushima, J. Hodgson, T.J. Nedwed, D.A. Palandro et al., Marine Pollut. Bull. 144, 160-166 (2019)

129. M.S. Conradi, S.A. Altobelli, N.J. Sowko, S.H. Conradi, E. Fukushima, J. Magn. Reson. 288, 95-99 (2018)

130. M.S. Conradi, S.A. Altobelli, N.J. Sowko, S.H. Conradi, E. Fukushima, J. Magn. Reson. 288, 23-27 (2018)

131. N. Bloembergen, E.M. Purcell, R.V. Pound, Phys. Rev. 73, 679-712 (1948)

132. M. Tseitlin, Z.L. Yu, R.W. Quine, G.A. Rinard, S.S. Eaton, G.R. Eaton, J. Magn. Reson. 249, 126-134 (2014)

133. S.S. Zalesskiy, E. Danieli, B. Blümich, V.P. Ananikov, Chem. Rev. 114, 5641-5694 (2014)

134. B. Saam, M.S. Conradi, J. Magn. Reson. 34, 67-71 (1998)

135. K. Takeda, J. Magn. Reson. 192, 218-229 (2008)

136. H.Y. Chen, Y. Kim, P. Nath, C. Hilty, J. Magn. Reson. 255, 100-105 (2015)

137. A. Asfour, in Practical Applications and Solutions Using LabVIEW Software, ed. by S. Folea (Intech Open, 2011) pp. 17-40

138. J.R. Biller, K.F. Stupic, A.B. Kos, T. Weilert, G.A. Rinard, Y. Nakashima, J. Moreland, er., Concepts Magn. Reson B 47B(1), e21350 (2017)

139. C. Michal, Concepts Magn. Reson B: Magn. Reson. Eng. 48B(3), e21401 (2018)

140. G. Jeschke, J. Magn. Reson. 306, 36-41 (2019)

141. J. Forrer, H. Schmutz, R. Tschaggelar, A. Schweiger, J. Magn. Reson. 166, 246-251 (2004)

142. J. Hyde, T. Camenisch, J. Ratke, R. Strangeway, W. Froncisz, in Biomedical EPR, Part B: Methodology, Instrumentation, and Dynamics. Biological Magnetic Resonance, vol 24/B, ed. by S.R. Eaton, G.R. Eaton, L.J. Berliner (Springer, Boston, MA, 2005) pp. 199-222. https://doi. org/10.1007/0-306-48533-8_7

143. R. Ahmad, S. Som, E. Kesselring, P. Kuppusamy, J.L. Zweier, L.C. Potter, J. Magn. Reson. 207, 322-331 (2010)

144. R.H. Pursley, G. Salem, N. Devasahayam, S. Subramanian, J. Koscielniak, M.C. Krishna et al., J. Magn. Reson. 178, 220-227 (2006) 
145. H. Sato-Akaba, M.C. Emoto, H. Hirata, H.G. Fujii, J. Magn. Reson. 284, 48-58 (2017)

146. H. Sato-Akaba, M. Tseytlin, J. Magn. Reson. 304, 42-52 (2019)

147. B. Epel (08/04/20) Specman4EPR. Available: http://www.specman4epr.com/

148. A. Doll, AIP Adv. 9, 115110 (2019)

149. J.R. Biller, Nitroxide radicals for low frequency electron paramagnetic resonance imaging (EPRI), $\mathrm{Ph} . \mathrm{D}$. Thesis, Chemistry and Biochemistry, University of Denver (2014)

150. J. McPeak, R.W. Quine, S.S., Eaton, G.R. Eaton, Rev. Sci. Instrum. 90(2), 024102 (2019)

151. A. Panchenko, H. Dilger, E. Möller, T. Sixt, E. Roduner, J. Power Sour. 127, 325-330 (2004)

152. A. Niemöller, P. Jakes, R.-A. Eichel, J. Granwehr, Chem. Phys. Lett. 716, 231-236 (2019)

153. B. Wang, V. Likodimos, A.J. Fielding, R.A.W. Dryfe, Carbon 160, 236-246 (2020)

154. D. Mannikko, S. Stoll, Energy Fuels 33, 4237-4243 (2019)

155. H. Wolfson, R. Ahmad, Y. Twig, A. Blank, P. Kuppusamy, in Proceedings of SPIE Medical Imaging: Applications in Molecular, Structural and Functional Imaging (Orlando, Florida, 21-26 February 2015) Paper 941706

156. H. Hou, N. Khan, S. Gohain, M.L. Kuppusamy, P. Kuppusamy, Biomed. Microdev. 20, 29 (2018)

157. P. Kuppusamy, Clinical Trial: Oxygen Measurements in Subcutaneous Tumors by EPR Oximetry Using OxyChip. Available: https://clinicaltrials.gov/ct2/show/NCT02706197 (2015)

158. A. Blank, P. Kuppusamy, A. Rizwan, Method and System for Electron Paramagnetic Resonance, US Patent (2017)

159. L.E. Switala, B.E. Black, C.A. Mercovich, A. Seshadri, J.P. Hornak, J. Magn. Reson. 285, 18-25 (2017)

160. O. Laguta, M. Tuček, J. van Slageren, P. Neugebauer, J. Magn. Reson. 296, 138-142 (2018)

161. P.R. Shrestha, N. Abhyankar, M.A. Anders, K.P. Cheung, R. Gougelet, J.T. Ryan et al., Anal. Chem. 91, 11108-11115 (2019)

162. Z. Chen, J. Sun, P. Wang, IEEE Trans. Magn. 53, 1-9 (2017)

163. S. Tamaru, K. Yakushiji, A. Fukushima, S. Yuasa, H. Kubota, IEEE Magn. Lett. 5, 1-4 (2014)

164. J. Anders, K. Lips, J. Magn. Reson. 306, 118-123 (2019)

165. J. Anders, A. Angerhofer, G. Boero, J. Magn. Reson. 217, 19-26 (2012)

166. J. Handwerker, B. Schlecker, U. Wachter, P. Radermacher, M. Ortmanns, J. Anders, in Proceedings of the 2016 IEEE International Solid-State Circuits Conference (ISSCC), (San Francisco, CA, 2016) pp. 476-477, https://doi.org/10.1109/ISSCC.2016.7418114

167. T. Yalcin, G. Boero, Rev. Sci. Instrum. 79, 094105 (2008)

168. G. Boero, G. Gualco, R. Lisowski, J. Anders, D. Suter, J. Brugger, J. Magn. Reson. 231, 133-140 (2013)

169. B. Schlecker, A. Hoffmann, A. Chu, M. Ortmanns, K. Lips, J. Anders, IEEE Sens. J. 19, 89959003 (2019)

170. A. Chu, B. Schlecker, K. Lips, M. Ortmanns, J. Anders, in Proceedings of the 2018 IEEE International Solid - State Circuits Conference - (ISSCC) (San Francisco, CA, 2018) pp. 354-356, https:// doi.org/10.1109/ISSCC.2018.8310330

171. W.R. Hagen, J. Magn. Reson. 44, 447-469 (1981)

172. D.O. Hearshen, W.R. Hagen, R.H. Sands, H.J. Grande, H.L. Crespi, I.C. Gunsalus et al., J. Magn. Reson. 69, 440-459 (1986)

173. P.J. Carl, S.C. Larsen, J. Phys. Chem. B. 104, 6568-6575 (2000)

174. W. Froncisz, J. S. Hyde, J. Magn. Reson. 47, 515 (1982)

175. C.S. Burns, E. Aronoff-Spencer, C.M. Dunham, P. Lario, N.I. Avdievich, W.E. Antholine et al., Biochemistry 41, 3991-4001 (2002)

176. J.S. Hyde, B. Bennett, E.D. Walter, G.L. Millhauser, J.W. Sidabras, W.E. Antholine, Biophys. J. 96, 3354-3362 (2009)

177. A. Kultaeva, V. Bon, M.S. Weiss, A. Pöppl, S. Kaskel, Inorg. Chem. 57, 11920-11929 (2018)

178. Y.-Q. Song, S. Utsuzawa, Y. Tang, J. Magn. Reson. 306, 109-111 (2019)

Publisher's Note Springer Nature remains neutral with regard to jurisdictional claims in published maps and institutional affiliations. 